\title{
Predictors of Posttraumatic Growth after High Risk Pregnancy
}

\author{
$\mathrm{Ju}$ Young $\mathrm{Ha}^{1}$ and Bo Yun Sim ${ }^{1}$ \\ College of Nursing, Pusan National University, Busandaehak-ro 49, \\ Yangsan-si, 626-870, Gyungsannamdo, Korea \\ jyha1028@pusan.ac.kr
}

\begin{abstract}
The aim of this study was to investigate the predictors of posttraumatic growth (PTG) after high risk pregnancy. Data were collected from 183 women who had obstetrical high risk using self-administered questionnaire including scales of Korean-Posttraumatic Growth Inventory (K-PTGI). Women were recruited from nine hospitals in P city, U city, and K-do in Korea, from February 2014 to December, 2014. Women with high risk during pregnancies reported PTG in a moderate degree after childbirth. PTG was significantly associated with maternal identity. Maternal identity, religion, age, and positive neonatal perception were significant predictors of PTG. The findings suggest that when promoting PTG of women with high risk during pregnancies, healthcare providers should adjust interventions to improve women's maternal identity and positive perception about newborns.
\end{abstract}

Keywords: Trauma, Growth, Pregnancy, Identity, Perception

\section{Introduction}

Childbirth is a positive experience for most women yet some women express distress after birth. In one study conducted in Atlanta (USA), 34-55\% of the women experienced their births as traumatic [1]. Some of the described risk factors for reporting traumatic experiences resulting from childbirth are high levels of obstetric intervention and the use of emergency procedures during birth [2]. The majority of research on childbirth has focused on negative outcomes, such as depression, anxiety disorder and more recently posttraumatic stress disorder [3]. However, positive psychological outcomes following childbirth had been found in previous studies. Half of the women reported at least a small or moderate degree of growth in response to childbirth [4-5].

Posttraumatic growth (PTG) is defined as a positive psychological change in one's belief or functioning change experienced as a result of the struggle with highly challenging life circumstances [6]. Tedeschi and Calhoun [6] identify three domains of posttraumatic growth: one's sense of self; interpersonal relationships; and existential issues. The domain of change in self implies a greater sense of resiliency, wisdom, strength and a greater acceptance of limitations. The change in relationships depicts an increased appreciation and sense of value of friends and family, increased compassion and altruism. Finally, change in existential issues encompasses a new appreciation of each day, changes in priorities and values and changes in spiritual beliefs. These positive changes are often reflected in personal strength, relational intimacy, sense of spirituality, appreciation of life and new possibilities [7]. Up to recently research in this area focused on posttraumatic growth following typically traumatic events, such as cancer [8], natural disasters [9-10], accident [11], military combat [12-13] and assault [14]. However, research on positive changes following childbirth is limited. Especially, the growth after childbirth among women who had obstetrical complications has not been explored. 
Examining psychological outcomes such as growth allows a more comprehensive account of psychological reactions following childbirth to be helped, which can inform maternal identity and perception of the newborn. Maternal identity refers to the recognition and emotions as a mother in the maternal and newborn relationship, which is formed through the process of psychosocial transition of becoming a mother after childbirth [15]. When maternal identity is positively formed, the woman can feel a sense of comfort as a mother and predict her baby's behavior patterns [16]. And maternal identity is expressed as positive perception for her baby [17]. Some studies of a positive maternal perception during the first months of life is no guarantee that there will be no difficulty in the future development of the newborn, but the lack of a positive maternal perception of the newborn may be associated with a high rate of problems in the child's emotional development [18]. Previous studies reported that posttraumatic growth was significantly correlated with demographic variables [19], degree of pain [20], personality and personal strengths [6], cognitive processes and coping strategies [21], social support, optimism [22], and socio-cultural factors [23]. However, posttraumatic growth after high risk pregnancy has not been sufficiently studied. To address the gap in knowledge in this issue, the current study had three objectives. One aim was to explore the prevalence of posttraumatic growth in women who underwent obstetrical prenatal high risk. The second was to explore the relationship between participant's posttraumatic growth and maternal identity and neonatal perception. The third one was to identify the prominent predictors of posttraumatic growth in women after high risk pregnancy.

\section{Method}

\subsection{Study Design}

This research was retrospective and cross-sectional. This study examined the predictors of posttraumatic growth in women after high risk pregnancy.

\subsection{Setting and Samples}

Ethical approval was obtained by the university Institutional Review Board. High risk pregnant women were recruited to participate through advertisement of nine hospitals in $\mathrm{P}$ city, U city and K-do in Korea, from February 2014 to December, 2014. The criteria to be eligible for inclusion in the study were as follows: (a) Age ( $\leq 19$ or $\geq 35$ ), (b) Multiple gestation, (c) Labor related problems (Preterm labor, Dystocia), (d) Pregnancy related Disease (Premature rupture of membranes, Placenta previa, Gestational diabetes, Gestational hypertension), and (e) Deformed baby. This study was carried out in compliance with ethical standards. When women agreed to participate this research, they were given consent forms and questionnaires. The investigator introduced the purpose of the study, described procedures, and explained the confidentiality of records to each participant. Of the 220 eligible women approached, only 183(83.2\%) actually completed the questionnaire.

\subsection{Measures}

\subsubsection{Posttraumatic Growth}

The posttraumatic growth was measured using the Posttraumatic Growth Inventory (PTGI) developed by Tedeschi, \& Calhoun [6] and translated into Korean by Song et al. [24]. The original Posttraumatic Growth Inventory (PTGI) [6] is a 21-item scale that measures the degree of reported positive change arising from the struggle with a traumatic 
event. Considering cultural differences between East and West, a 16-item Korean version of Posttraumatic Growth Inventory was used to obtain data. K-PTGI consists of four subscales: Changed Perception of Self, Relating to Others, New Possibilities, and Spiritual Change. Each item is rated by the respondent on a 6-point Likert scale from 0 ("I did not experience this change at al") to 5("I experienced this change to a very great degree"). The internal consistency of the 16-item inventory evaluated by Cronbach's alpha, was 0.91 [9]. In this study, the internal consistency reliability using Cronbach's alpha was 0.89 .

\subsubsection{Maternal Identity}

Maternal identity was measured using the Maternal Identity Inventory developed by Kim [25]. This inventory consists of 17-items rated on a 5-point Likert scale (1 to 5) with higher scores indicating positive identity about self as a mother. The internal consistency of the inventory evaluated by Cronbach's alpha, was 0.94 [25]. In present study, the Cronbach's alpha was 0.95 .

\subsubsection{Perception of the Newborn}

Perception of the newborn was measured using the Perception of the Newborn Inventory developed by Broussard [26] and translated into Korean by Lee [27]. This inventory consists of 15-items rated on a 5-point Likert scale from 1("agree strongly") to 5("disagree strongly") with higher scores indicating higher positive perceptions of newborns. The internal consistency of the inventory evaluated by Cronbach's alpha, was 0.79 [27]. In present study, the Cronbach's alpha was 0.83 .

\subsection{Data Analysis}

The data were analyzed with PASW win 18.0 program and $\mathrm{p}<0.05$ was considered statistically significant. Descriptive statistics such as frequency, mean and standard deviation were used to describe the general characteristics and Obstetrical characteristics of this study. Independent sample t-test and one-way ANOVA were used to analyze the difference of general and obstetrical characteristics by posttraumatic growth, maternal identity and perception of the newborn. Prevalence of PTG of participants, we used Schroevers and Teo's method [28] where PTGI items were dichotomized into: 0 for those between 'not at all' and 'small degree' (answer rating 0,1 or 2) and 1 for those between 'moderate degree' and 'very great degree' (answer rating 3,4 or)5. This score was used only for descriptive purpose. And Pearson correlation coefficients were calculated to identify the relationships between posttraumatic growth and influencing variables. Stepwise multiple regression analysis was done to identify the influencing factors of posttraumatic growth. Before performing the multiple regression analysis, multicollinearity test was done to check whether the degree of interrelatedness of the independent variables in this study is problematic or not. As a result of multicollinearity test, the range of tolerance was verified as 0.98 to 0.99 (evaluation criteria is >0.1), variation inflation factor was 1.010 to 1.022 (evaluation criteria is <10) and condition index was 2.01 to 20.64 (evaluation criteria is $<30$ ). This analysis satisfied the suggested values of multicollinearity evaluation for regression analysis.

\section{Results}

\subsection{Participant Characteristics}

Participants were 183 women who had obstetrical high risk. Women were aged between 20 and $52(\mathrm{M}=32.76, \mathrm{SD}=4.68)$. In case of religion, 86(47.0\%) people answered 
'none', 'Buddhists' were 64(35\%), and 'Christians' were 23(12.6\%). More than half of the participants had jobs 112(61.2\%), introverted personality 94(51.4\%), and planned pregnancy $103(57.2 \%)$. Number of children ranged from 0 to $3(\mathrm{M}=1.50, \mathrm{SD}=0.77)$.

Gestational age ranged from 25 to 42 weeks $(M=36.79, S D=3.81)$. In case of delivery type, 86(47.0\%) people answered 'normal vaginal delivery', and 97(53.0\%) people answered 'Caesarean section'. In case of Baby's Health, 149(81.4\%) people answered 'Healthy', and 34(18.6\%) people answered 'Unhealthy'. In case of high-risk pregnancy type, 30(16.4\%) people answered 'Two or more obstetrical risk factors', 'Age( $\leq 19$ or $\geq$ $35)$ ' were $25(13.7 \%)$, 'Premature rupture of membranes' were 16(8.7\%), 'Preterm labor' were 15(8.2\%), and 'Multiple gestation' were 13(7.1\%). Sixty two (33.9\%) women perceived labor as traumatic experience. Mean score of labor pain was 7.20 out of 10 and that of postpartum pain was 5.37 out of 10 .

\subsection{Degree of Independent Variables}

\subsubsection{Posttraumatic Growth}

Women who had obstetrical high risk reported K-PTGI in a moderate to high degree frequently $(\mathrm{M}=56.05, \mathrm{SD}=11.55$; total range 2-80), with an average item score of 3.50 . Mean scores on the subscales were as follows: Changed Perception of Self $(\mathrm{M}=22.56$, $\mathrm{SD}=4.67$, range from 0 to 30 , with an average item score of 3.76), Relating to Others $(\mathrm{M}=17.92, \mathrm{SD}=3.88$, range from 0 to 25 , with an average item score of 3.58), New Possibilities $(\mathrm{M}=11.17, \mathrm{SD}=2.86$, range from 1 to 15 , with an average item score of 3.72), and Spiritual Change $(\mathrm{M}=4.40, \mathrm{SD}=2.87$, range from 0 to 10 , with an average item score of 2.20) (Table 1).

\subsubsection{Maternal Identity and Perception of the Newborn}

Women who had obstetrical high risk reported maternal identity in a moderate to high degree frequently $(\mathrm{M}=68.36, \mathrm{SD}=11.67$; total range 34-85). Perception of the newborn of women were negative perception about their baby $(\mathrm{M}=-1.60, \mathrm{SD}=5.52$; total range -21-19) (Table 1).

Table 1. Degree of Posttraumatic Growth, Maternal Identity and Neonatal Perception

\begin{tabular}{lcccrr}
\hline & $\begin{array}{c}\text { Number of } \\
\text { items }\end{array}$ & $\begin{array}{c}\text { Possible scores } \\
\text { range }\end{array}$ & $\begin{array}{c}\text { Obtained } \\
\text { scores }\end{array}$ & M \pm SD & Items M \pm SD \\
\hline PTG & 16 & $0-80$ & $2-80$ & $56.05 \pm 11.55$ & $3.50 \pm 0.72$ \\
Changed perception of self & 6 & $0-30$ & $0-30$ & $22.56 \pm 4.67$ & $3.76 \pm 0.78$ \\
Relating to others & 5 & $0-25$ & $0-25$ & $17.92 \pm 3.88$ & $3.58 \pm 0.78$ \\
New possibility & 3 & $0-15$ & $1-15$ & $11.17 \pm 2.86$ & $3.72 \pm 0.95$ \\
Spiritual change & 2 & $0-10$ & $0-10$ & $4.40 \pm 2.87$ & $2.20 \pm 1.44$ \\
Maternal identity & 17 & $17-85$ & $34-85$ & $68.36 \pm 11.67$ & $4.02 \pm 0.69$ \\
Neonatal perception & 15 & $-60-60$ & $-21-19$ & $-1.60 \pm 5.52$ & $-0.04 \pm 0.37$ \\
\hline
\end{tabular}

PTG; Posttraumatic Growth

\subsection{Posttraumatic Growth, Maternal Identity and Perception of the Newborn depend on General and Obstetrical Characteristics}

There were significant differences between posttraumatic growth and age ( $\mathrm{t}=-2.54$, $p=.012)$, religion $(\mathrm{F}=4.55, p=.002)$, number of children $(\mathrm{F}=4.19, p=.007)$ newborn's health status $(\mathrm{t}=2.38, p=.019)$ and postpartum pain $(\mathrm{F}=2.56, p=.040)$. Post-hoc analysis result showed that posttraumatic growth for religion showed the highest score from Christians, which were significantly higher than none. Number of children showed the 
highest score from two children, which were significantly higher than only one child. There was no significant difference with postpartum pain.

There were significant differences between maternal identity and personality $(\mathrm{t}=2.52$, $p=.013)$, baby's health $(\mathrm{t}=3.82, p<.001)$, traumatic experience $(\mathrm{t}=-2.04, p=.042)$ and postpartum pain $(\mathrm{F}=2.79, p=.028)$. Post-hoc analysis did not show a significant difference.

There were significant differences between perception of the newborn and delivery type ( $\mathrm{t}=-2.26, p=.025)$, baby's health $(\mathrm{t}=-2.11, p=.037)$. Post-hoc result did not show a significant difference (Table 2).

Table 2. PTG, MI and PN depend on General and Obstetrical Characteristics $\mathrm{n}=\mathbf{1 8 3}$

\begin{tabular}{|c|c|c|c|c|c|c|c|c|c|}
\hline \multirow[t]{2}{*}{ Variable } & \multicolumn{3}{|c|}{ PTG } & \multicolumn{3}{|c|}{ Ml } & \multicolumn{3}{|c|}{ NP } \\
\hline & $\mathrm{M} \pm \mathrm{SD}$ & t or $F$ & $p$ & $\mathrm{M} \pm \mathrm{SD}$ & t or $F$ & $p$ & $\mathrm{M} \pm \mathrm{SD}$ & t or $F$ & $p$ \\
\hline \multicolumn{10}{|l|}{ Age(year) } \\
\hline $20 \sim 34$ & $54.62 \pm 10.95$ & -2.54 & .012 & $67.95 \pm 11.42$ & -.70 & .483 & $-2.00 \pm 5.38$ & -1.46 & .147 \\
\hline$\geq 35$ & $59.23 \pm 12.30$ & & & $69.26 \pm 12.27$ & & & $-.72 \pm 5.78$ & & \\
\hline \multicolumn{10}{|l|}{ Religion } \\
\hline None $\mathrm{a}^{\mathrm{a}}$ & $53.33 \pm 10.86$ & 4.55 & .002 & $67.35 \pm 11.70$ & 1.12 & .351 & $-.76 \pm 5.32$ & 1.35 & .254 \\
\hline Buddhists $^{\mathrm{b}}$ & $56.45 \pm 12.61$ & & $* \mathrm{a}<\mathrm{c}$ & $68.55 \pm 12.61$ & & & $-1.86 \pm 5.78$ & & \\
\hline Christians $^{\mathrm{c}}$ & $63.70 \pm 8.82$ & & & $68.52 \pm 9.16$ & & & $-3.43 \pm 5.80$ & & \\
\hline Catholics $^{\mathrm{d}}$ & $57.50 \pm 5.37$ & & & $75.88 \pm 8.36$ & & & $-2.88 \pm 3.98$ & & \\
\hline Others ${ }^{\mathrm{e}}$ & $67.00 \pm 8.49$ & & & $74.00 \pm 14.14$ & & & $-3.50 \pm 4.95$ & & \\
\hline \multicolumn{10}{|l|}{ Job } \\
\hline Yes & $57.08 \pm 10.75$ & -.96 & .338 & $69.31 \pm 11.55$ & -.88 & .382 & $-1.99 \pm 4.04$ & .82 & .411 \\
\hline No & $55.40 \pm 12.03$ & & & $67.76 \pm 11.76$ & & & $-1.36 \pm 6.29$ & & \\
\hline \multicolumn{10}{|l|}{ Personality } \\
\hline Extroverted & $56.38 \pm 12.20$ & .37 & .710 & $70.56 \pm 12.23$ & 2.52 & .013 & $-1.60 \pm 6.05$ & .01 & .989 \\
\hline Introverted & $55.74 \pm 10.96$ & & & $66.28 \pm 10.77$ & & & $-1.61 \pm 5.01$ & & \\
\hline \multicolumn{10}{|l|}{ Planned Pregnancy } \\
\hline Yes & $57.30 \pm 9.40$ & 1.60 & .113 & $69.07 \pm 11.81$ & .94 & .349 & $-1.13 \pm 5.95$ & 1.34 & .182 \\
\hline No & $54.42 \pm 13.78$ & & & $67.43 \pm 11.49$ & & & $-2.23 \pm 4.87$ & & \\
\hline \multicolumn{10}{|l|}{ Other children } \\
\hline $0^{\mathrm{a}}$ & $53.42 \pm 9.29$ & 4.19 & .007 & $66.42 \pm 9.81$ & .81 & .490 & $2.25 \pm 8.85$ & 2.42 & .067 \\
\hline $1^{\mathrm{b}}$ & $54.44 \pm 11.42$ & & $* b<c$ & $67.42 \pm 12.33$ & & & $-2.20 \pm 5.15$ & & \\
\hline $2^{c}$ & $59.85 \pm 8.38$ & & & $69.06 \pm 10.44$ & & & $-1.38 \pm 5.42$ & & \\
\hline 3 or more ${ }^{\mathrm{d}}$ & $51.84 \pm 18.39$ & & & $71.42 \pm 13.75$ & & & $-2.11 \pm 4.16$ & & \\
\hline \multicolumn{10}{|l|}{ Gestational Age (Week) } \\
\hline$<34$ & $54.92 \pm 12.67$ & .25 & .783 & $66.77 \pm 13.54$ & .46 & .629 & $-.23 \pm 7.15$ & 2.72 & .068 \\
\hline $35 \sim 38$ & $56.50 \pm 11.10$ & & & $68.68 \pm 10.75$ & & & $-1.24 \pm 4.59$ & & \\
\hline $38 \sim 42$ & $56.24 \pm 11.47$ & & & $68.89 \pm 11.52$ & & & $-2.63 \pm 5.21$ & & \\
\hline \multicolumn{10}{|l|}{ Type of delivery } \\
\hline Normal & $55.59 \pm 10.6$ & -.51 & .612 & $68.35 \pm 11.34$ & -.013 & .990 & $-2.57 \pm 6.09$ & -2.26 & .025 \\
\hline Caesarean section & $56.46 \pm 12.35$ & & & $68.37 \pm 12.02$ & & & $-.74 \pm 4.84$ & & \\
\hline \multicolumn{10}{|l|}{ Baby's Health } \\
\hline Healthy & $57.01 \pm 10.24$ & 2.38 & .019 & $70.14 \pm 10.42$ & 3.82 & $<.001$ & $-2.05 \pm 5.44$ & -2.11 & .037 \\
\hline Unhealthy & $51.79 \pm 15.83$ & & & $60.36 \pm 13.86$ & & & $.15 \pm 5.43$ & & \\
\hline \multicolumn{10}{|l|}{ Type of High-risk } \\
\hline \multicolumn{10}{|l|}{ Pregnancy } \\
\hline $\operatorname{Age}(\leq 19$ or $\geq 35)$ & $59.44 \pm 10.78$ & 11.13 & .339 & $72.20 \pm 11.49$ & 1.06 & .394 & $-2.36 \pm 6.50$ & .39 & .966 \\
\hline Multiple gestation & $60.69 \pm 8.19$ & & & $72.08 \pm 7.83$ & & & $-.62 \pm 4.61$ & & \\
\hline $\begin{array}{l}\text { Premature rupture of } \\
\text { membranes }\end{array}$ & $49.44 \pm 19.56$ & & & $67.00 \pm 13.08$ & & & $-.81 \pm 6.32$ & & \\
\hline Preterm labor & $53.73 \pm 7.55$ & & & $66.13 \pm 10.93$ & & & $-.73 \pm 7.16$ & & \\
\hline Placenta previa & $56.00 \pm 6.93$ & & & $63.83 \pm 11.84$ & & & $.00 \pm 3.35$ & & \\
\hline Hypertension & $59.33 \pm 11.98$ & & & $69.50 \pm 12.76$ & & & $-.17 \pm 2.56$ & & \\
\hline Dystocia & $59.00 \pm 10.97$ & & & $69.50 \pm 11.80$ & & & $-3.13 \pm 4.42$ & & \\
\hline Ultrasound diagnosis & $60.63 \pm 12.31$ & & & $63.63 \pm 7.35$ & & & $-3.25 \pm 3.20$ & & \\
\hline Others & $54.90 \pm 10.40$ & & & $69.14 \pm 12.28$ & & & $-2.12 \pm 5.57$ & & \\
\hline Multiple responses & $55.67 \pm 11.55$ & & & $65.53 \pm 12.33$ & & & $-1.33 \pm 5.57$ & & \\
\hline \multicolumn{10}{|l|}{ Traumatic } \\
\hline Yes & $54.32 \pm 11.28$ & -1.46 & .147 & $65.92 \pm 12.62$ & -2.04 & .042 & $-.63 \pm 5.53$ & 1.71 & .088 \\
\hline $\mathrm{N}$ & $56.94 \pm 11.63$ & & & $69.61 \pm 11.00$ & & & $-2.10 \pm 5.48$ & & \\
\hline \multicolumn{10}{|l|}{ Labor pain (Range 1-10) } \\
\hline $1 \sim 2$ points & $58.80 \pm 11.72$ & .54 & .705 & $68.87 \pm 10.03$ & .37 & .833 & $-.27 \pm 5.91$ & .88 & .479 \\
\hline $3 \sim 4$ points & $58.86 \pm 10.34$ & & & $67.86 \pm 13.64$ & & & $-.43 \pm 2.88$ & & \\
\hline $5 \sim 6$ points & $56.80 \pm 13.56$ & & & $70.34 \pm 12.18$ & & & $-2.23 \pm 4.54$ & & \\
\hline $7 \sim 8$ points & $54.76 \pm 10.20$ & & & $67.42 \pm 10.97$ & & & $-.97 \pm 6.27$ & & \\
\hline
\end{tabular}




\begin{tabular}{|c|c|c|c|c|c|c|c|c|c|}
\hline $9 \sim 10$ points & $55.95 \pm 11.83$ & & & $68.13 \pm 12.40$ & & & $-2.31 \pm 5.36$ & & \\
\hline \multicolumn{10}{|c|}{ Postpartum pain (Range 1-10) } \\
\hline $1 \sim 2$ points & $59.67 \pm 12.93$ & 2.56 & .040 & $72.88 \pm 10.42$ & 2.79 & .028 & $-3.83 \pm 5.03$ & 1.91 & .111 \\
\hline $3 \sim 4$ points & $55.43 \pm 7.84$ & & & $64.35 \pm 9.70$ & & & $-2.78 \pm 3.33$ & & \\
\hline $5 \sim 6$ points & $57.27 \pm 11.58$ & & & $70.03 \pm 10.77$ & & & $-.96 \pm 6.13$ & & \\
\hline $7 \sim 8$ points & $51.83 \pm 12.71$ & & & $65.43 \pm 13.47$ & & & $-.67 \pm 5.71$ & & \\
\hline $9 \sim 10$ points & $58.13 \pm 6.40$ & & & $67.93 \pm 12.01$ & & & $-2.27 \pm 4.27$ & & \\
\hline
\end{tabular}

\subsection{Correlation of Posttraumatic Growth, Maternal Identity and Perception of the Newborn}

The correlation between posttraumatic growth and maternal identity was significant $(\mathrm{r}=.41, p<.001)$. Positive correlations were found between maternal identity and changed perception of self $(\mathrm{r}=.51, p<.001)$, relating to others $(\mathrm{r}=.33, p<.001)$, new possibility $(\mathrm{r}=.18, p=.011)$, and spiritual change $(\mathrm{r}=.21, p=.004)$ (Table 3$)$.

Table 3. Correlations of PTG, MI and PN

\begin{tabular}{|c|c|c|c|c|c|c|c|}
\hline & $\begin{array}{l}\text { PTG } \\
\mathrm{r}(p)\end{array}$ & $\begin{array}{l}\mathrm{CP} \\
\mathrm{r}(p)\end{array}$ & $\begin{array}{l}\mathrm{RO} \\
\mathrm{r}(p)\end{array}$ & $\begin{array}{l}\text { NPo } \\
\mathrm{r}(p)\end{array}$ & $\begin{array}{l}\mathrm{SC} \\
\mathrm{r}(p)\end{array}$ & $\begin{array}{l}\text { MI } \\
\mathrm{r}(p)\end{array}$ & $\begin{array}{l}\mathrm{NP} \\
\mathrm{r}(p)\end{array}$ \\
\hline$\overline{\mathrm{PTG}}$ & & & & & & & \\
\hline $\mathrm{CP}$ & " .90 & & & & & & \\
\hline RO & $\begin{array}{c}(<.001) \\
\because .87 \\
(<.001)\end{array}$ & $\begin{array}{c}“ .75 \\
(<.001)\end{array}$ & & & & & \\
\hline NPo & “.75 & " .57 & " .52 & & & & \\
\hline SC & $\begin{array}{c}(<.001) \\
. .64 \\
(<.001)\end{array}$ & $\begin{array}{c}(<.001) \\
.40 \\
(<.001)\end{array}$ & 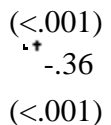 & $\begin{array}{l}{ }^{*}-.36 \\
(<.001)\end{array}$ & & & \\
\hline MI & " .41 & ". .51 & ". 33 & ${ }^{+} .18$ & ". .21 & & \\
\hline NP & $\begin{array}{c}-.001) \\
(.185)\end{array}$ & $\begin{array}{c}-.07 \\
(.345)\end{array}$ & $\begin{array}{c}(4.001) \\
-.10 \\
(.171)\end{array}$ & $\begin{array}{c}(.001) \\
-.04 \\
(.524)\end{array}$ & $\begin{array}{c}(.004) \\
-.09 \\
(.195)\end{array}$ & $\begin{array}{c}-.04 \\
(.519)\end{array}$ & \\
\hline
\end{tabular}

PTG; Posttraumatic Growth, MI; Maternal Identity, NP; Neonatal Perception, CP; Changed perception of self, RO; Relating to others, NPo; New possibility, SC; Spiritual change

\subsection{Predictors of Posttraumatic Growth}

Stepwise multiple regression analysis was used to examine simultaneously the relation of several predictors to the dependent variable of maternal identity. Seven independent variables associated with the maternal identity in the univariate analysis were put into a multiple regression analysis. Among these independent variables, 4 variables were included in the regression model, and posttraumatic growth was significantly predicted by transitional gratification to maternal identity $(\beta=.40, p<.001)$, religion $(\beta=.23, p=.001)$, age $(\beta=.16, p=.015)$, and neonatal perception $(\beta=-.16, p=.014)$. Overall, combinations of predictors accounted for $26.7 \%$ of the variance in posttraumatic growth among women with high risk during pregnancies (Table 4).

Table 4. Predictors of PTG

\begin{tabular}{lcccccc}
\hline & $\mathrm{B}$ & Std. Error & $\beta$ & $\mathrm{T}(p)$ & $\mathrm{F}(p)$ & Adjusted R2 \\
\hline MI & .394 & .063 & .398 & $6.244(<.001)$ & $17.58(<.001)$ & .26 \\
Christians $^{\mathrm{a}}$ & 7.834 & 2.219 & .225 & $3.530(\quad .001)$ & &
\end{tabular}




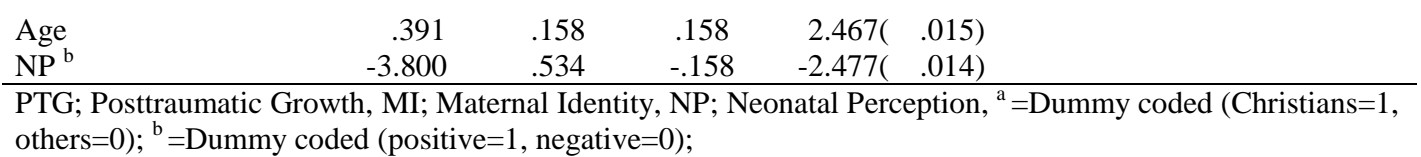

\section{Discussion}

The results of this study contribute to the growing literature demonstrating that developmental events such as childbirth do result in growth, with women reporting at least a moderate-to-great degree of growth. The level of posttraumatic growth of the study participants was 56.05 points. Comparison with previous research suggests levels of growth are higher for those reporting female infertility 32.42 [29], after a violent experience 40.66 [30], and breast cancer 53.88 [24]. All five domains of growth were endorsed, with the 'Changed perception of self' domain showing the most change. Women reported the least amount of growth in the 'Spiritual change' domain. This pattern is similar to the previous studies on growth in postnatal women [4]. But there was a slight difference in inventory according to cultural differences. Asian traditional culture has recognized the 'Appreciation of life' in the inclusion of the inventory of Korea, which is included in the 'Changed perception of self' domain. Growth was reported in three of the four domains measured in this study, with the greatest change in changed perception of self. This result is similar to the findings of Hardin \& Buckner [3]; if women recognized this as a positive experience after childbirth, they reported positive results, such as on satisfaction, encouragement and well-being. The lowest change was in spiritual change, implying that after childbirth spiritual development is less likely to occur in comparison to other changes.

In this study, growth was only associated with age, religion, other children, baby's health, and postpartum pain. The demographic variable related to growth was age with older participants reporting higher levels of growth than younger participants. This is contrary to the finding of previous studies following a range of events [4, 6]. It is unclear why this is, but possible explanations are that older high-risk pregnancies can lead to low growth owing to dangerous pregnancies and childbirth. However, a relationship between age and growth has not been reported consistently across studies [32]. Another factor associated with positive psychological growth is the religiosity of an individual. The growth of the Christian participants was higher than non-religious participants. This is consistent with previous studies following a range of events [33]. Spirituality can help individuals because most religions have developed their own framework through which trauma can be viewed as meaningful [34]. Another factor associated with growth is other children. The growth with only one child was higher than 2 children of participants. This is consistent with previous studies following a range of events [35]. First, it is the past experienced childbirth that had already experience growth. Second, if your child requires a lot of effort to take care of her, she will consume too much energy and growth will be more difficult [35]. Another factor associated with growth is the other baby's health. The growth of the unhealthy was higher than that of healthy participants. There is no research to compare national and international trends. But in Choi and An [36], caregivers caring for unhealthy children have been shown to experience high stress. The results show that the stress of the childbirth of the mother in unhealthy children can be estimated to be very high. Finally, another factor associated with growth is the other postpartum pain. To date, research has not confirmed results regarding the relationship between growth outcomes and postpartum pain. Future research therefore needs to further clarify possible factors in the relationship between growth and postpartum pain.

In this study, multiple regression analysis was used to establish a prediction equation. As a result, the regression model including maternal identity, religion, age, and neonatal perception was found to be significant. We found that maternal identity was a strong 
explaining factor in posttraumatic growth, which is very meaningful in that this is the first work to explore the influences of maternal identity on posttraumatic growth. Childbirth women may experience various difficulties and confusion while adapting to their new roles as a mother [37]. Also women who perceived a higher level of stress tend to feel less satisfied in taking up the maternal role and feel role-related conflict [38]. If women are conflicted about their role without experiencing growth in childbirth as a mother, it may cause confusion in the formation of maternal identity [37]. The findings of this study also supported the view of the concept that PTG adds a new perspective to childbirth.

\section{Conclusion}

The results of this study show that posttraumatic growth in women with high risk during pregnancies is significantly predicted by maternal identity, religion, age, and neonatal perception. From these results, it is concluded that nursing interventions for promoting posttraumatic growth of high risk pregnancy should focus on the education and support for understanding of maternal identity, religion, age, and neonatal perception. Moreover, the study results suggest the possibility that interventions for promoting PTG program for high risk pregnant women should be considered relating factors. And clinicians working with women who had prenatal complications should pay to attention to increase the growth in all dimensions of PTG. Further studies are needed to develop such interventions and verify their effects. And more research is needed to identify other possible determinants of growth in women following childbirth.

\section{Limitation}

When interpreting the results of this investigation, several limitations should be taken into consideration. First, the findings of this study are generalizable only to Korean women who experienced high risk pregnancies. Also, current sample was relatively small which limit the generalizability of these results. A second limitation is the cross-sectional and retrospective research design. The nature of this study prevented identification of causal relationships. Thirdly, the amount of overall explainable variance of $26.7 \%$ in PTG is rather than small. Therefore, further studies should be replicated in a more diverse sample, and field would benefit from prospective and longitudinal studies.

\section{Acknowledgements}

The authors would like to thanks to the women who agreed to take part in the study.

\section{References}

[1] J. E. Soet, G. A. Brack and C. Dilorio, "Prevalence and predictors of women's experience of psychological trauma during childbirth", vol.30, no.1, (2003), pp.36-46.

[2] D. Segal-Engelchin, O. Sadrid and J. Cwikel, "Pregnancy, childbirth and postpartum experiences of Israel women in the Negev", Journal of Prenatal \& Perinatal Psychology \& Health, vol.24, no.1, (2009), pp.3.

[3] I. Brockington, "Postpartum psychiatric disorders", The Lancet, vol.363, (2004), pp.303-310.

[4] A. Sawyer and S. Ayers, "Post-traumatic growth in women after childbirth", Psychology and Health, vol.24, no.4, (2009), pp.457-471.

[5] A. Sawyer, S. Ayers, D. Young, R. Bradley and H. Smith, "Posttraumatic growth after childbirth: A prospective study", Psychology and Health, vol.27, no.3, (2012), pp.362-377.

[6] R. G. Tedeschi and L. G. Calhoun, "The post traumatic growth inventory: measuring the positive legacy of trauma", Journal of Traumatic Stress, vol.9, no.3, (1996), pp.455-471.

[7] Y. Wang, H. Wang, J. Wang, J. Wu and X. Liu, "Prevalence and predictors of posttraumatic growth in accidentally injured patients", Journal of Clinical Psychology in Medical Settings, vol.20, no.1, (2013), pp.3-12. 
[8] A. M. Turner-Sack, R. Menna, S. R. Setchell, C. Maan and D. Cataudella, "Posttraumatic growth, coping strategies and psychological distress in adolescent survivors of cancer", Journal of Pediatric Oncology Nursing, vol.29, no.2, (2012), pp.70-79.

[9] G. S. Hafstad, V. Gil-Rivas, R. P. Kilmer and S. Raeder, "Parental adjustment, family functioning, and posttraumatic growth among Norwegian children and adolescents following a natural disaster", American Journal of Orthopsychiatry, vol.80, no.2, (2010), pp.248-257.

[10] A. M. Rhodes and T. V. Tran, "Predictors of posttraumatic stress and growth among black and white survivors of Hurricane Katrina: Does perceived quality of the governmental response matter?", Journal of Race and Social Problems, vol.4, (2012), pp.144-57.

[11] S. Rabe, A. Beauducel, T. Zollner, A. Maercker and A. Karl, "Regional brain electrical activity in posttraumatic stress disorder after motor vehicle accident", Journal of Abnormal Psychology, vol.115, (2006), pp.687-698.

[12] A. Feder, S. M. Southwick, R. R. Goetz, Y. Wang, A. Alonso, B. W. Smith, K. R. Buchholtz, T. Waldeck, R. Ameli, J. Moore, R. Hain, D. S. Charney and M. Vythilingam, "Posttraumatic growth in former Vietnam prisoners of war", Psychiatry, vol.71, no.4, (2008), pp.359-370

[13] S. Kimhi, Y. Eshel, L. Zysberg and S. Hantman, "Postwar winners and losers in the long run: determinants of war related stress symptoms and posttraumatic growth", Community Mental Health Journal, vol.46, (2010), pp.10-19.

[14] P. Frazier, A. Conlon and T. Glaser, "Positive and negative life changes following sexual assault", Journal of Consulting and Clinical Psychology, vol.69, (2001), pp.1048-1055.

[15] H. B. Fontenot, "Transition and adaptation to adoptive motherhood", Journal of Obstetric, Gynecologic, and Neonatal Nursing, vol.36, (2007), pp.175-182.

[16] R. T. Mercer and L. O. Walker, "A review of nursing interventions to foster becoming a mother", Journal of Obstetric, Gynecologic, and Neonatal Nursing, vol.35, (2006), pp.568-582.

[17] R. Rubin, "Maternal identity and the maternal experience", Springer Publishers, New York (1984).

[18] E. R. Broussard, Primary prevention works, issues in children's and families' leves. Thousand Oaks, vol.6, (1997), pp.87-115.

[19] J. Biere and D. Elliott, "Prevalence, characteristics, and long-term sequelae of natural disaster exposure in the general population”, Journal of Traumatic Stress, vol.13, (2000), pp.661-679.

[20] P. A. Linley and S. Joseph, "Positive change following trauma and adversity: A review", Journal of Traumatic Stress, vol.17, (2004), pp.11-21.

[21] A. W. Evers, F. W. Kraaimaat, W. Van Lankweld, P. J. Jongen, J. W. G. Jacobs and J. W. J. Bijlsma, "Beyond unfavorable thinking: The Illness Cognition Questionnaire for chronic diseases", Journal of Consultin and Clinical Psychology, vol.69, (2001), pp.1026-1036.

[22] G. Prati and L. Pietrantoni, "Optimism, social support, and coping strategies as factors contributing to posttraumatic growth: A meta-analysis", Journal of Loss and Trauma, vol.14, no.5, (2009), pp.364-388.

[23] C. L. Park, S. Lechner, L. G. Calhoun and R. G. Tedeschi, "Measurement issues in assessing growth following stressful life experiences", Handbook of posttraumatic growth, Lawrence Erlbaum Associates Publishers. Mahwah, NJ, (2006), pp.47-67.

[24] S. H. Song, H. S. Lee, J. H. Park and K. H. Kim, "Validity and reliability of the Korean version of the posttraumatic growth inventory", Journal Helath Psychol, vol.14, (2009), pp.193-214.

[25] H. W. Kim, "Model Construction of Maternal Identity in Primi-gravida", Journal of Korean Academy of Nursing, vol.28, no.2, (1998), pp.510-518.

[26] E. R. Broussard, "Assessment of the adaptive potential of the mother-infant system: the neonatal perception inventories", Seminars in Perinatology, vol.3, no.1, (1979), pp.91-100.

[27] J. H. Lee, "A Study on Assessment of Mothers' Perception of a Newborn Baby", Journal of Korean Academy of Nursing, vol.16, no.3, (1987), pp.67-77.

[28] M. J. Schroevers and I. Teo, "The report of posttraumatic growth in Malaysian cancer patients: Relationships with psychological distress and coping strategies", Psychooncology, vol.17, (2008), pp.1239-1246.

[29] J. H. Yeo, "Childbirth Experience of Participants in Lamaze Childbirth Education", Journal of Korean Academy of Womens Health Nursing, vol.16, no.3, (2010), pp.215-223.

[30] A. Grubaugh and P. Resick, "Posttraumatic growth in treatment-seeking female assault victims. Psychiatric Quarterly, vol.78, (2007), pp.145-155.

[31] A. M. Hardin and E. B. Buckner, "Characteristics of a positive birth experience for women who have unmedicated childbirth", Journal of Perinatal Education, vol.13, no.4, (2004), pp.10-16.

[32] C. M. Aldwin, M. R and L. L. Kelly, "Life span developmental perspectives on stress-related growth", Positive Life Changes in the Context of Medical Illness, Washington, (2009), pp.87-104.

[33] I. J. Lee, “A Systematic review of posttraumatic growth in cancer", Social Work Practice and Research, vol.6, (2009), pp.81-113

[34] N. Mascaro and D. H. Rosen, "The role of existential meaning as a buffer against stress", Journal of Humanistic Psychology, vol.46, (2006), pp.168-190.

[35] H. J. Kim, J. H. Kwon, J. N. Kim, R. Lee and K. S. Lee, "Posttraumatic growth and related factors in breast cancer survivors", The Korean Journal of Psychotherapy, vol.13, no.3, (2008), pp.781-799. 
[36] S. M. Choi and C. I. An, "Posttraumatic growth, Quality of Life and Stress Coping in Mothers of the child with Muscular Dystrophy", The Korean Psychological Association, (2007), pp.256-257.

[37] M. C. Logsdon, K. L. Wisner and M. D. Pinto-Foltz, "The impact of postpartum depression on mothering", Journal of Obstetric, Gynecologic, and Neonatal Nursing, vol.35, (2006), pp.652-658.

[38] R. Hassall, J. Rose and J. McDonald, "Parenting stress in mothers of children with an intellectual disability: The effects of parental cognitions in relation to child characteristics and family support", Journal of Intellectual Disability Research, vol.49, (2005), pp.405-418.

\section{Authors}

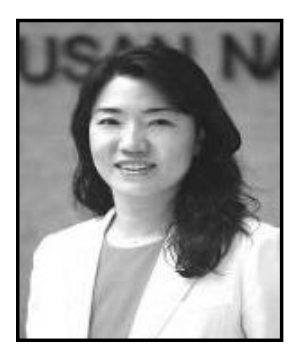

\section{Ju-Young Ha}

Associate Professor, College of Nursing, Pusan National University

Ph.D. in Adult Nursing, College of Nursing Science, Ewha Womans University, Seoul, Korea, 2007

Director of Publication Board, Korean Gerontological Nurses

Association, April, 2013-April, 2015

Member of Board of Scientific Program, Korean Society of Women Health Nursing, Jan. 2014-Dec. 2015

Reviewer, 「Korean Journal of Women Health Nursing $\lrcorner$, Jan. 2012-Present

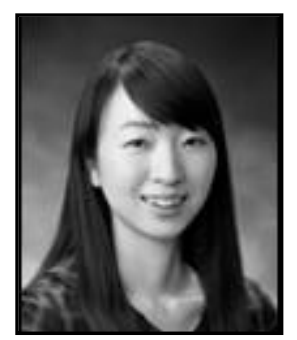

\section{Bo-Yun Sim}

Doctoral student, College of Nursing, Pusan National University Lecturer, College of Nursing, Pusan National University, 2015 